\title{
Cortical Synaptogenesis and Motor Map Reorganization Occur during Late, But Not Early, Phase of Motor Skill Learning
}

\author{
Jeffrey A. Kleim, Theresa M. Hogg, Penny M. VandenBerg, Natalie R. Cooper, Rochelle Bruneau, and Michael Remple \\ Canadian Centre for Behavioural Neuroscience, Department of Psychology and Neuroscience, University of Lethbridge, Lethbridge, Alberta, \\ Canada T1K 3M4
}

\begin{abstract}
Extensive motor skill training induces reorganization of movement representations and synaptogenesis within adult motor cortex. Motor skill does not, however, develop uniformly across training sessions. It is characterized by an initial fast phase, followed by a later slow phase of learning. How cortical plasticity emerges during these phases is unknown. Here, we examine motor map topography and synapse number within rat motor cortex during the early and late phases of motor learning. Adult rats were placed in either a skilled or unskilled reaching condition (SRC and URC, respectively) for 3, 7, or $10 \mathrm{~d}$. Intracortical microstimulation of layer $\mathrm{V}$ was used to determine the topography of forelimb movement representations within caudal forelimb area of motor cortex contralateral to the trained paw. Quantitative electron microscopy was used to measure the number of synapses per neuron within layer V. SRC animals showed significant increases in reaching accuracy after 3, 7, and $10 \mathrm{~d}$ of training. In comparison with URC animals, SRC animals had significantly larger distal forelimb representations after $10 \mathrm{~d}$ of training only. Furthermore, SRC animals had significantly more synapses per neuron than URC animals after 7 and $10 \mathrm{~d}$ of training. These results show that both motor map reorganization and synapse formation occur during the late phase of skill learning. Furthermore, synaptogenesis precedes map reorganization. We propose that motor map reorganization and synapse formation do not contribute to the initial acquisition of motor skills but represent the consolidation of motor skill that occurs during late stages of training.
\end{abstract}

Key words: motor cortex; plasticity; learning; synaptogenesis; motor map; intracortical microstimulation; rat

\section{Introduction}

Most adult behavior involves the expression of motor skill. Despite the significance of motor learning for the performance of most behaviors, little is known as to how or where skilled movement is encoded by the brain. The motor cortex is arguably the primary motor structure and is essential for performance of skilled movement (Porter and Lemon, 1995). Since the discovery of motor maps within the motor cortex (Fritsch and Hitzig, 1870), decades of experiments have shown that redistribution of movement representations occurs in response to a variety of manipulations (for review, see Sanes and Donoghue, 2000). However, the capacity for reorganization likely exists to support acquisition of skilled movement. Indeed, motor learningdependent changes in movement representations have been demonstrated in human (Cohen et al., 1993; Pearce et al., 2000),

Received July 22, 2003; revised Nov. 14, 2003; accepted Nov. 15, 2003.

This work was supported by the Canadian Institutes of Health Research, the Natural Sciences and Engineering Research Council of Canada, the Alberta Heritage Foundation for Medical Research, and the Canadian Stroke Network. We thank Shannon Gibbs for assistance with animal training as well as Bryan Kolb and Cristina Alberini for thoughtful comments on this manuscript.

Correspondence should be addressed to Dr. Jeffrey A. Kleim, Canadian Centre for Behavioural Neuroscience, Department of Psychology and Neuroscience, University of Lethbridge, 4401 University Drive, Lethbridge, Alberta, Canada T1K3M4. Email: jeffrey.kleim@uleth.ca.

D0I:10.1523/JNEUROSCI.3440-03.2004

Copyright $\odot 2004$ Society for Neuroscience $\quad$ 0270-6474/04/240628-06\$15.00/0 monkey (Nudo et al., 1996b), and rodent (Kleim et al., 1998a; Remple et al., 2001; Conner et al., 2003) motor cortex. The reorganization is characterized by both an areal expansion and an increase in the number of representations corresponding to trained movements (Nudo et al., 1996a; Kleim et al., 1998a, 2002b; Conner et al., 2003). The changes are also learning specific. Neither repetition of unskilled movements (Kleim et al., 1998a; Plautz et al., 2000), strength training (Remple et al., 2001) nor exercise training (Kleim et al., 2002a) is sufficient to induce motor map reorganization. Furthermore, manipulations that prevent map reorganization also impair skill learning (Conner et al., 2003). Collectively, these data demonstrate that the development of skilled movement is supported by changes in motor map topography. It is unknown, however, whether motor map reorganization develops uniformly as training progresses or occurs during specific phases of training.

The development of motor skill is characterized by two general phases of learning. The first involves rapid improvements in performance that can be observed both within a single training session and across the first few sessions. The second slower phase involves more moderate gains in performance that progress across multiple training sessions (Kleim et al., 1996; Nudo et al., 1996b; Karni et al., 1998; Kleim et al., 1998a). Results from neural imaging studies have suggested that these two different phases are supported by different patterns of activity across the motor sys- 
tem (Karni et al., 1998). The initial fast phase is associated with activation of striatum and cerebellum, whereas the later phase engages motor cortex (Ungerleider et al., 2002). These results would then predict that motor map reorganization would occur during the late, rather than early, phase. Furthermore, changes in cortical synapse number have been shown to be both localized to regions of motor cortex that undergo reorganization (Kleim et al., 2002b) and only detectable during the late phase (Kleim et al., 1996). We, therefore, hypothesize that motor map reorganization and synapse formation occurs during the late, slower phase of motor learning. To test this hypothesis, we examined the topography of movement representations and synapse number within rat forelimb motor cortex during both the early and late phases of motor learning.

\section{Materials and Methods}

Subjects. Fifty-six adult male Long-Evans hooded rats (350-420 gm) were assigned randomly to either a skilled reaching condition (SRC; $n=$ 28 ) or an unskilled reaching condition (URC; $n=28)$. SRC animals were further allocated into $3 \mathrm{~d}(n=9), 7 \mathrm{~d}(n=10)$, and $10 \mathrm{~d}(n=9)$ training conditions. URC animals were similarly allocated to $3 \mathrm{~d}(n=9), 7 \mathrm{~d}(n=$ $9)$, and $10 \mathrm{~d}(n=10)$ training conditions. Animals were group housed (four animals/cage) in standard laboratory cages on a $12 \mathrm{hr}$ light/dark cycle throughout the experiment within the Canadian Centre for Behavioural Neuroscience vivarium.

Reach training. Over the course of several days, all animals were placed on a restricted diet until they reached $90 \%$ of their original body weight. A brief period of pretraining was then given to familiarize the rats with the reaching task. This involved placing them into test cages $(10 \times 18 \times$ $10 \mathrm{~cm}$ ) with floors constructed of $2 \mathrm{~mm}$ bars, $9 \mathrm{~mm}$ apart edge to edge. A $4 \mathrm{~cm}$ wide and $5 \mathrm{~cm}$ deep tray filled with food pellets ( $45 \mathrm{mg}$; Bioserv) was mounted on the front of the cage. The rats were required to reach outside the cage and retrieve pellets from the tray. All rats remained in pretraining until they had successfully retrieved 10 pellets $(\sim 1 \mathrm{hr} / \mathrm{d}$ for $2 \mathrm{~d})$. After pretraining, the rats were placed into a Plexiglas cage $(11 \times 40 \times 40 \mathrm{~cm})$ with a $1 \mathrm{~cm}$ slot located at the front of the cage. SRC animals were trained for $15 \mathrm{~min}$ each day to reach through the slot and retrieve food pellets from a table outside the cage (Whishaw and Pellis, 1990). Rats were permitted to use either limb, and the preferred limb was noted for each animal. Each session was videotaped, and frame by frame analysis was used to assess reaching performance. A successful reach was scored when an animal grasped the food pellet, brought it into the cage and to its mouth without dropping the pellet. The percentage of successful reaches [(number of successful retrievals/the total number of reaches $) \times 100]$ was then calculated.

To control for the potential effects of increased motor activity, URC animals were trained on a variation of the skilled reaching task. They were placed into training cages identical to that of the SRC and also trained to reach for a food pellet placed outside the slot for 15 min per day. However, the pellet was placed out of reach. Thus, the URC animals would reach for but never obtain the food pellet and, therefore, not develop skilled reaching movements. To keep the animals reaching, a food pellet would be periodically dropped into the training cage through the slot. Thus, the SRC and URC animals experienced similar amounts of forelimb activity, but only the SRC animals developed motor skill. Pilot work showed that well trained URC animals performed at the level of previously untrained animals when placed into the SRC (our unpublished observations).

Performance on the skilled reaching task used here is characterized by an early phase of learning in which reaching accuracy improves rapidly for over the first $5 \mathrm{~d}$ of training. After this phase, reaching accuracy improves at a much slower rate. Based on these data, we defined the first $5 \mathrm{~d}$ as the early, rapid phase of learning and the second $5 \mathrm{~d}$ as the late, slow phase. Animals from both the SRC and URC conditions were, therefore, trained for 3,7 , or 10 consecutive days before being mapped to assess the topography of movement representations during these different phases.

Electrophysiological mapping. Within $2 \mathrm{~d}$ of the final training session, standard intracortical microstimulation techniques were used to generate detailed maps of forelimb regions of the motor cortex contralateral to the trained forelimb (Kleim et al., 1998a; Remple et al., 2001). Before surgery, animals were anesthetized with ketamine hydrochloride $(70 \mathrm{mg} /$ $\mathrm{kg}$, i.p.) and xylazine ( $5 \mathrm{mg} / \mathrm{kg}$, i.p.), receiving acepromazine $(0.02 \mathrm{mg} /$ $\mathrm{kg}$, i.m.) and ketamine $(20 \mathrm{mg} / \mathrm{kg}$, i.p.) as needed. A craniotomy was performed over the motor cortex contralateral to the trained paw of each animal. To prevent edema, a small puncture was made in the cisterna magna before removing the skull and dura. The exposed cortex was then covered in warm silicone oil $\left(37^{\circ} \mathrm{C}\right)$. A digital image of the cortical surface was taken, and a $375 \mu \mathrm{m}$ grid was superimposed onto the image. A glass microelectrode (controlled by a hydraulic microdrive) was used to make systematic penetrations across the cortex using the cortical surface image and grid as a guide. At each penetration site, the electrode was lowered to $\sim 1550 \mu \mathrm{m}$ (corresponding to cortical layer V). Stimulation consisted of $13200 \mu \mathrm{sec}$ cathodal pulses delivered at $350 \mathrm{~Hz}$ from an electrically isolated stimulation circuit. Animals were maintained in a prone position with the limb consistently supported. Sites where no movement was detected at $\leq 60 \mu \mathrm{A}$ were recorded as unresponsive. Forelimb movements were classified as either distal (wrist/digit) or proximal (elbow/ shoulder), and representational maps were generated from the pattern of electrode penetrations. The caudal forelimb area (CFA) was chosen for analysis because this area has previously been shown to reorganize in response to skilled forelimb training (Kleim et al., 1998a). The CFA was defined by a medial boundary of vibrissa representations, a lateral and caudal boundary of nonresponse sites, and a rostral boundary of head and neck representations (Kleim et al., 1998a; Remple et al., 2001; Kleim et al., 2002a). An image analysis program (CANVAS, version 3.5) was used to calculate the areal extent of the CFA. The proportion of both distal and proximal movement representations that occupied the CFA was then calculated.

Tissue preparation. Immediately after mapping, a small volume of Toluidine blue (2\%) was injected into the medial and lateral boundaries of the CFA. Animals were deeply anesthetized with pentobarbital $(120 \mathrm{mg} /$ $\mathrm{kg}$ ) and transcardially perfused with $2 \%$ paraformaldehyde $/ 2.5 \%$ glutaraldehyde in $0.1 \mathrm{M}$ phosphate buffer. The mapped hemisphere was then sectioned coronally $(300 \mu \mathrm{m})$ on a vibratome and viewed under a dissection microscope at low power $(2 \times)$. Samples of tissue $(\sim 500 \mu \mathrm{m}$ wide $)$ extending from pia to white matter were taken from sections in which the dye injections were visible. The tissue blocks were then washed in $0.1 \mathrm{M}$ cacodylate, postfixed in $2 \%$ osmium tetroxide $/ 1.5 \%$ potassium ferrocyanide in $0.1 \mathrm{M}$ cacodylate buffer for $2 \mathrm{hr}$, and en bloc stained with $2 \%$ uranyl acetate for $45 \mathrm{~min}$. Samples were then dehydrated through a series of alcohols before being transferred into propylene oxide and gradually embedded in Eponate resin. All tissue samples were coded with respect to treatment condition, and stereological analysis was conducted by independent researchers (N.R.C., R.B., and M.R.) who were all blind to sample conditions.

Estimating changes in synapse number. Behavioral training can lead to an increase in cortical volume that is primarily attributable to dendritic (Greenough et al., 1985; Kleim et al., 1997b), glial (Sirevaag et al., 1991; Anderson et al., 1994), and vascular hypertrophy (Black et al., 1990). Because of this volume increase, measures of synapse density alone may not reveal changes in synapse number. In conditions of stable neuron number, however, changes in neuropil volume can be detected by estimating neuron density. By obtaining the density of neurons and the density of synapses per unit volume, the number of synapses per neuron can be calculated and used to measure changes in synapse number (Turner and Greenough, 1985; Black et al., 1990; Kleim et al., 1996, 1998b; Jones et al., 1999). In the present study, unbiased stereological measures were used to determine the number of synapses per neuron within layer $\mathrm{V}$ of the motor cortex.

Neuron density. One block of tissue from each animal was chosen randomly, and 120 serial $1 \mu \mathrm{m}$ sections were taken using a diamond knife and an ultramicrotome. These sections were stained with Toluidine blue, and cortical layer $\mathrm{V}$ was identified by the presence of large pyramidal cells and the absence of layer IV granule cells. Using a computer-assisted microscope, the physical disector (Sterio, 1984) was used to obtain estimates of neuron density. Pairs of sections within each series were com- 

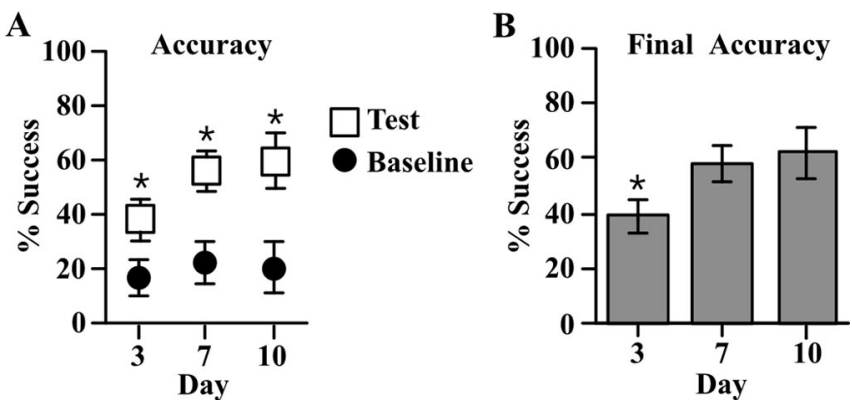

Figure 1. A, Performance of animals on the skilled reaching task after 3,7, or $10 \mathrm{~d}$ of training. Closed circles represent performance on the first day of training (Baseline), and open squares represent performance on the last day of training (Test). In comparison with baseline levels, all animals showed a significant increase in the percentage of successful reaches on the test day $\left({ }^{*} p<0.05\right.$; Student's dependent $t$ test). $B$, Performance on the last day of training for all three training durations. Reaching accuracy did not significantly differ between the 7 and $10 \mathrm{~d}$ animals, but both were significantly higher than the $3 \mathrm{~d}$ animals $\left({ }^{*} p<0.05\right.$; Fisher's PLSD).

pared in succession. The first section in the series was considered the Reference section, and the second the Lookup section, then the second section became the Reference section for the third section, and so on. Neuronal nuclei were identified by the presence of a central nucleolus within a pale nucleus and frequently by the oval to pyramidal shape of the surrounding cell soma. Irregularly shaped, smaller nuclei with extensive chromatin characteristic of glial cells were not counted. Within an unbiased counting frame $\left(2500 \mu \mathrm{m}^{2}\right.$ at $\left.60 \times\right)$, the number of neuronal nuclei that were present in the Reference section, but not the Lookup section $\left(\mathrm{Q}^{-}\right)$, were counted. The disector volume of tissue through which the cells were counted $\left(\mathrm{V}_{\text {dis }}\right)$ was given by: $V_{\text {dis }}=\left(A_{\text {frame }}\right)(H)$, where $A_{\text {frame }}$ was the area of the counting frame and $\mathrm{H}$ was the section thickness (1 $\mu \mathrm{m})$ multiplied by the number of sections. Neuron density $\left(\mathrm{Nv}_{\text {Neuron }}\right)$ was then determined by:

$$
N v_{\text {Neuron }}=\frac{\mathrm{Q}^{-}}{\mathrm{V}_{\mathrm{dis}}} .
$$

Synapse density. After $1 \mu \mathrm{m}$ sectioning, a small pyramid was trimmed into layer $\mathrm{V}$ of the motor cortex using a $1 \mu \mathrm{m}$ Toluidine blue section from that block as a guide. From the pyramid, 20 silver-gray, serial sections $(\sim 70 \mathrm{~nm}$ thick) were taken using a diamond knife and an ultramicrotome. Sections were collected on Formvar-coated, slotted, copper grids and stained with lead citrate-uranyl acetate. A four picture photomicrograph montage $(23,800 \times$ print magnification) was taken from the same position within each section. The physical disector (Sterio, 1984) was then used to estimate synapse density from these micrographs. Briefly, pairs of electron micrographs (70 nm apart) within the series were then compared, and the number of synapses, within an unbiased counting of a known area $\left(66 \mu \mathrm{m}^{2}\right)$, that were present in the Reference section but not the Lookup section were counted. Synapses were identified by the presence of a synaptic membrane specialization and at least three vesicles in the presynaptic element. From these measures, the number of synapses per neuron could be determined $\left(\mathrm{Nv}_{\text {Synapse }}\right)\left(1 / \mathrm{Nv}_{\text {Neuron }}\right)$ (Kleim et al., 1996).

\section{Results}

\section{Skilled reaching performance}

Within each daily 15 min training session, rats made $185( \pm 14)$ reaching attempts. Paired Student's $t$ tests $(p<0.05)$ were conducted on the percentage of successful reaches between the first and last day of training for SRC animals in each of the three different training schedules. Results showed a significant increase in reaching success after $3 \mathrm{~d}\left(\mathrm{t}_{(7)}=5.037 ; p<0.05\right), 7 \mathrm{~d}\left(\mathrm{t}_{(9)}=\right.$ 12.39; $p<0.05)$, and $10 \mathrm{~d}\left(\mathrm{t}_{(12)}=12.89 ; p<0.05\right)$ of training (Fig. 1A). After $3 \mathrm{~d}$ of training, performance improved from $18 \%$ $( \pm 7 \%)$ to $39 \%$ ( $\pm 8 \%)$. After $7 \mathrm{~d}$, accuracy increased from $23 \%$

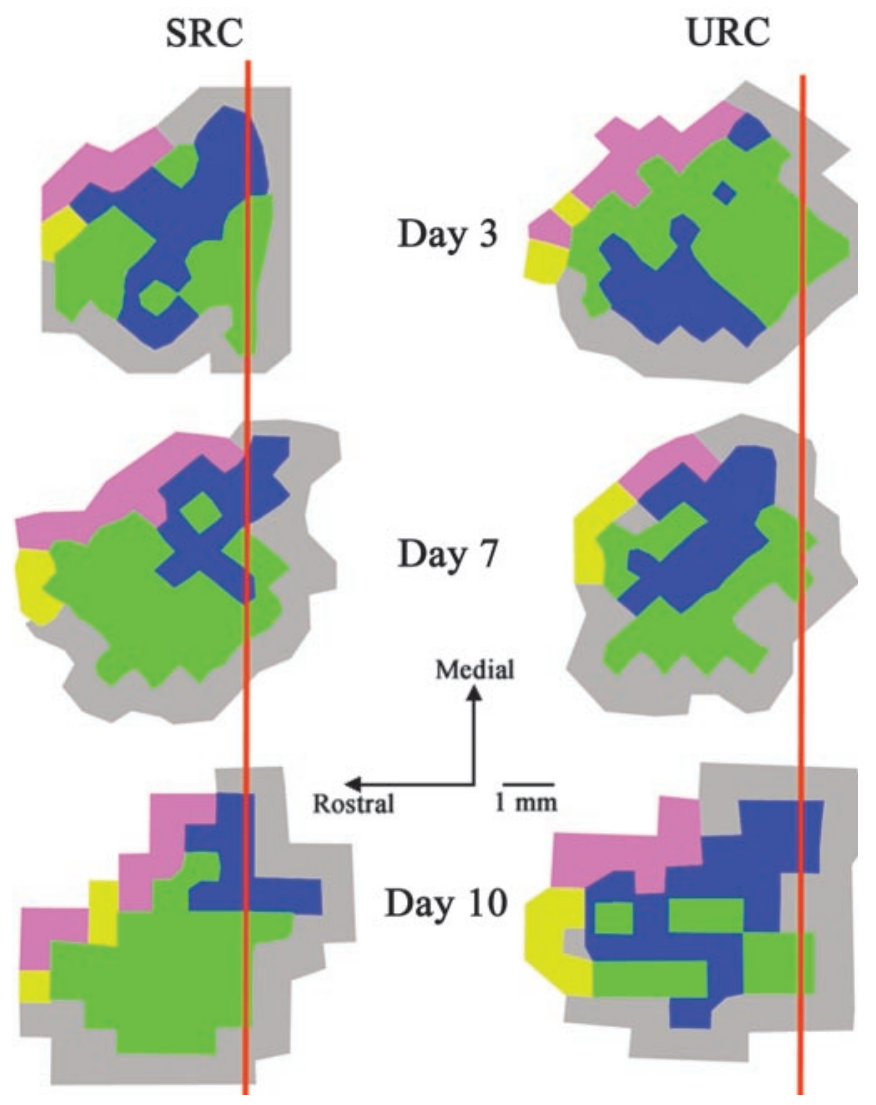

Figure 2. Representative motor maps from SRC and URC animals after 3, 7, and $10 \mathrm{~d}$ of training. SRC animals exhibited a significant increase in the proportion of the CFA occupied by distal movement (green) representations in comparison with URC animals after $10 \mathrm{~d}$ of training. URC animals had a significantly greater proportion of CFA occupied by proximal movement (blue) than SRC animals after $10 \mathrm{~d}$ of training. Vibrissae representations are shown in purple, head/neck representations are shown in yellow, and nonresponse sites are shown in gray. Bregma is indicated by a red line.

( $\pm 8 \%$ ) to $52 \%$ ( $\pm 7 \%)$, and after $10 \mathrm{~d}$, accuracy improved from $21 \%( \pm 5 \%)$ to $61 \%( \pm 9 \%)$. An ANOVA showed a significant effect of "day" on final reaching accuracy $\left(F_{(2,39)}=4.11 ; p<\right.$ 0.05 ). Subsequent multiple comparisons (Fisher's PLSD; $p<$ 0.05 ) showed SRC animals in the $3 \mathrm{~d}$ condition had significantly lower reaching accuracies than the 7 and $10 \mathrm{~d}$ animals (Fig. $1 B$ ). The results show that although significant improvements in reaching accuracy occurred after $3 \mathrm{~d}$, additional significant improvements can be seen after $7 \mathrm{~d}$.

\section{Topography of movement representations}

Each evoked motor map was derived from $\sim 78( \pm 13)$ electrode penetrations. CFA maps were located approximately between -0.5 and $+4.5 \mathrm{~mm}$ bregma (Fig. 2). An ANOVA with "condition" and day as between-subject factors revealed no significant main effect of condition $\left(F_{(1,84)}=0.85 ; p>0.05\right)$, day $\left(F_{(4,84)}=\right.$ $1.78 ; p>0.05)$, or condition $\times$ day $\left(F_{(4,84)}=0.59 ; p>0.05\right)$ on total area of the CFA (Fig. 3, left). However, a significant condition $\times$ day interaction was found for the percentage of the CFA occupied by distal $\left(F_{(4,84)}=5.12 ; p<0.05\right)$ and proximal $\left(F_{(4,84)}=\right.$ 5.12; $p<0.05)$ movement representations. Subsequent multiple comparisons (Fisher's PLSD; $p<0.05$ ) showed SRC animals to have a significantly greater proportion of CFA occupied by distal representations (Fig. 3, middle) and a significantly smaller proportion occupied by proximal representations (Fig. 3, right) than 

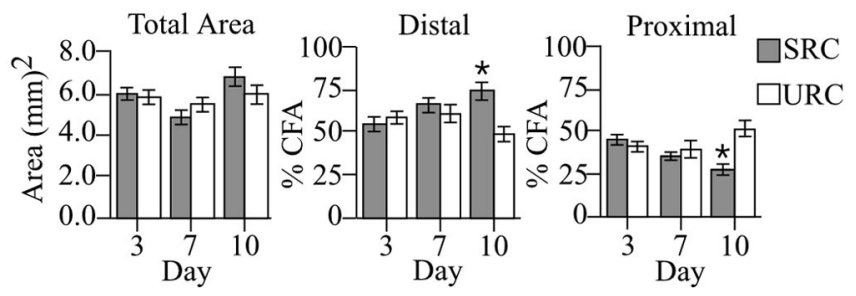

Figure 3. Left, Total area of the CFA in SRC and URC animals in the three different training schedules. The mean percentage of the (FA \pm SEM occupied by distal (middle) and proximal (right) forelimb movement representations. SRC animals had a significantly greater proportion of the CFA occupied by distal movement representations than the URC animals after $10 \mathrm{~d}$ of training ( ${ }^{*} p<0.05$; Fisher's PLSD). Conversely, URC animals had a significantly greater proportion of the CFA occupied by proximal movement representations than SRC animals after $10 \mathrm{~d}$ $\left({ }^{*} p<0.05 ;\right.$ PLSD $)$

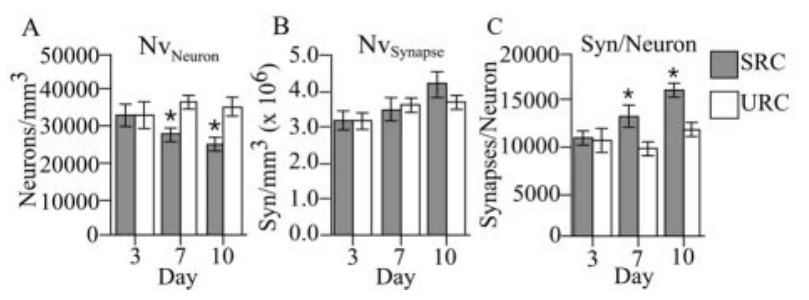

Figure 4. Neuron density $\left(\mathrm{Nv}_{\text {neuron }}\right)(A)$, synapse density $\left(\mathrm{Nv}_{\text {synapse }}\right)(B)$, and number of synapses per neuron (Syn/Neuron) ( $($ ) within layer V of the CFA. SRC animals had a significantly lower density of neurons than URC animals after 7 and $10 \mathrm{~d}$ of training ( ${ }^{*} p<0.05$; Fisher's PLSD). No significant differences in synapse density were found between SRC and URC animals in any of the three training schedules. SRC animals had significantly more synapses per neuron than URC animals after 7 and $10 \mathrm{~d}$ of training ( ${ }^{*} p<0.05$; Fisher's PLSD).

URC animals. The data demonstrate that despite significant increases in reaching performance after 3 and $7 \mathrm{~d}$ of training, significant map reorganization did not occur until after $10 \mathrm{~d}$ of training.

\section{Synapses per neuron}

For each animal, a total of $80(+8)$ disector pairs were used to count $124(+9)$ neurons through a volume of $2.98 \times 10^{6}$ $\left(+2.11 \times 10^{5}\right) \mu \mathrm{m}^{3}$ (coefficient of error, 0.064). Approximately $37(+3)$ disector pairs were used to count $87(+4)$ synapses through volume of $205(+12) \mu \mathrm{m}^{3}$ for each animal (coefficient of error, 0.065). Two-way ANOVA revealed a significant time $\times$ condition interaction on neuron density $\left(F_{(2,39)}=3.29 ; p<0.05\right.$ and number of synapses per neuron $\left(F_{(2,39)}=3.83 ; p<0.05\right)$. Synapse density did significantly differ as a function of condition or time $\left(F_{(2,39)}=0.91 ; p>0.05\right)$. Subsequent multiple comparisons (Fisher's PLSD; $p<0.05$ ) showed the SRC animals to have a significantly lower neuron density than URC animals after 7 and 10, but not 3, days (Fig. 4A). Despite the decrease in neuron density, SRC animals maintained synapse density (Fig. 4B), resulting in a significant increase in the number of synapses per neuron after 7 and $10 \mathrm{~d}$ of training (Fig. 4C). The decrease in neuron density is attributable to neuropil expansion (resulting from glial and dendritic hypertrophy) rather than a loss of neurons. Thus, the fact that synapse density did not change despite an increase in neuropil volume is consistent with an increase in synapse number that is reflected as an increase in the number of synapses per neuron on days 7 and 10 .

\section{Discussion}

Understanding the neural mechanisms of learning requires not only identifying those neurobiological changes that occur after learning but also determining how such changes occur during development of the learned behavior. The nature and locus of these changes may vary as a function of time. For example, Rose and colleagues (Clements and Rose, 1996; Rose and Stewart, 1999) have used a chick model of passive avoidance conditioning to show that during learning there are time-dependent shifts in neural activity and neurochemistry that occur across different brain regions. Similarly, time-limited shifts in the role of different thalamic nuclei occur during discriminative avoidance conditioning in rabbits (Hart et al., 1997). Here, we show that reorganization of motor maps and synaptogenesis within the motor cortex during motor skill training does not occur during the initial fast phase of learning but rather during the second, slower phase of learning when the rate of gain of performance is much lower. These data demonstrate that specific forms of learningdependent neural plasticity can be temporally dissociated from specific learning-dependent changes in behavior.

\section{Synaptogenesis occurs after motor skill acquisition}

Dendritic and synaptic hypertrophy within the motor cortex after extensive motor skill training has been well documented (Greenough et al., 1985; Withers and Greenough, 1989; Kleim et al., 1996; Jones et al., 1999). The present results show that during training on a skilled forelimb reaching task, significant increases in synapse number within the motor cortex are not detectable until after significant skill acquisition has occurred. Despite the fact that SRC animals exhibited a significant increase in reaching accuracy after $3 \mathrm{~d}$, the number of synapses per neuron within the motor cortex did not significantly differ from URC animals. This is consistent with previous work showing similar increases in synapse number after extensive training on a more complex motor learning task (Kleim et al., 1996). This may reflect the fact that other motor structures are more critically engaged during the early phase of training or that the changes in the motor cortex during the early phase of learning do not involve synapse formation.

During the initial phases of training, improvements in performance may be supported by plasticity within other motor structures such as the cerebellum or striatum (Ungerleider et al., 2002). Indeed, motor training has been shown to induce synaptogenesis within these brain areas (Black et al., 1990; Comery et al., 1995; Kleim et al., 1997a,b). However, the motor cortex is clearly engaged during the early phase of learning. Significant increases in immediate early gene expression occur during the early stages of motor learning (Kleim et al., 1996), and changes in neuronal ensemble activity within the motor cortex are both observable during the initial training phase and directly predict performance (Laubach et al., 2000). It is also possible that plasticity within the motor cortex during the early phase may not involve increases in synapse number. Such plasticity might include changes in the efficacy of existing synapses (Rioult-Pedotti et al., 1998) or increases in neuronal excitability (Aou et al., 1992).

\section{Motor map reorganization occurs after motor skill acquisition}

Despite significant improvements in reaching accuracy after 3 and $7 \mathrm{~d}$ of training, significant expansion of distal movement representations within the motor cortex was not detectable until after $10 \mathrm{~d}$ of training. Distinct changes in motor cortex activity have been observed after very limited amounts of motor training (Niemann et al., 1991; Karni et al., 1998; Gandolfo et al., 2000), indicating changes in cortical function do occur during the initial learning phase. The changes in neural activity likely reflect the 
encoding of novel movement patterns (Laubach et al., 2000) and may be supported by changes in synaptic strength (RioultPedotti et al., 1998). However, they do not seem to reflect changes in cortical movement representations. It is possible that subtle changes in map topography occur during the acquisition of skills that are not detectable with the microstimulation techniques used. However, if small changes in map organization occur during the first week of training, they do not parallel the large improvements in reaching accuracy observed within the same time frame.

Reorganization of movement representations has been shown to occur within minutes in response to a variety of manipulations, including blockade of GABA receptors (Jacobs and Donoghue, 1991) and electrical stimulation (Nudo et al., 1990; VandenBerg and Kleim, 2001). Thus, the cortex maintains the capacity for rapid reorganization; yet, here we show that reorganization in response to motor training requires more than one week. It is possible that during the initial training experience, changes in movement representations occur, but do not persist, outside of the training session. Classen et al. (1998) have shown changes in movement representations after a single motor training session that last for several minutes before reverting to the pretraining state. Because the motor maps in the present experiment were derived several hours after training, such transient changes would be missed. Regardless, changes in map topography that endure beyond the training session are not detectable until after $10 \mathrm{~d}$ of training.

It is possible is that map reorganization simply requires a sufficient amount of time after the onset of training to be detected. In support of this second interpretation, Galvan and Weinberger (2002) have shown that experience-dependent plasticity within the auditory cortex after a single session of auditory discrimination training induces receptive field reorganization that evolves for several days after training. An additional explanation is that motor map reorganization is related to some change in motor performance other than an increase in movement accuracy. Indeed, the development of accurate movement may then be followed by qualitative changes in movement kinematics associated with movement refinement, the development of which does not affect accuracy. For example, movement sequences may be adapted so as to become more efficient or rapid without significantly affecting accuracy. Motor map reorganization may reflect such changes in performance. Conner et al. (2003) have recently shown that significant improvements in reaching accuracy can occur in the absence of changes in motor map area. The depletion of cortical acetylcholine via immunotoxic lesioning of the nucleus basalis of Meynert significantly impaired, but did not abolish, increases in reaching accuracy. The authors suggest that motor map plasticity may contribute to learning efficiency. If, indeed, motor map reorganization reflected an increase in the capacity for skill learning, then we would expect the plasticity to precede rather than follow the initial rapid increase in reaching accuracy. An alternative explanation is that map reorganization requires not only the acquisition of skilled movement but sufficient repetition of those movements. In support of this idea, we have recently found that removing animals from motor training during the early phase of training, when significant increases in reaching accuracy have occurred, prevented later motor map reorganization. Animals allowed to perform the acquired movements did, however, exhibit motor map reorganization (J.A.K. and T.M.H., unpublished observations).

In conclusion, the present experiment demonstrates that skill learning is associated with synapse formation and motor map reorganization within the motor cortex. However, these changes are not linearly related to improvements in motor performance because they occur during the late, slow phase of learning rather than during the early fast phase. The results demonstrate the temporally dynamic nature of learning-dependent plasticity that occurs within a single brain region during training on a single task and show how different phases of learning may be supported by different forms of plasticity.

\section{References}

Anderson BJ, Li X, Alcantara AA, Isaacs KR, Black JE, Greenough WT (1994) Glial hypertrophy is associated with synaptogenesis following motor-skill learning, but not with angiogenesis following exercise. Glia 11:73-80.

Aou S, Woody CD, Birt D (1992) Increases in excitability of neurons of the motor cortex of cats after rapid acquisition of eye blink conditioning. J Neurosci 12:560-569.

Black JE, Isaacs KR, Anderson BJ, Alcantara AA, Greenough WT (1990) Learning causes synaptogenesis, whereas motor activity causes angiogenesis, in cerebellar cortex of adult rats. Proc Natl Acad Sci USA 87:5568-5572.

Classen J, Liepert J, Wise SP, Hallett M, Cohen LG (1998) Rapid plasticity of human cortical movement representation induced by practice. J Neurophysiol 79:1117-1123.

Clements MP, Rose SP (1996) Time-dependent increase in release of arachidonic acid following passive avoidance training in the day-old chick. J Neurochem 67:1317-1323.

Cohen LG, Brasil-Neto JP, Pascual-Leone A, Hallett M (1993) Plasticity of cortical motor output organization following deafferentation, cerebral lesions, and skill acquisition. Adv Neurol 63:187-200.

Comery TA, Shah R, Greenough WT (1995) Differential rearing alters spine density on medium-sized spiny neurons in the rat corpus striatum: evidence for association of morphological plasticity with early response gene expression. Neurobiol Learn Mem 63:217-219.

Conner JM, Culberson A, Packowski C, Chiba AA, Tuszynski MH (2003) Lesions of the basal forebrain cholinergic system impair task acquisition and abolish cortical plasticity associated with motor skill learning. Neuron 38:819-829.

Fritsch G, Hitzig E (1870) Uber die elektrische Erregbarkeit des Grosshirns. Arch Anatomie Physiol Wiss Med Lpz 37:300-332.

Galvan V, Weinberger N (2002) Long-term consolidation and retention of learning-induced tuning plasticity in the auditory cortex of the guinea pig. Neurobiol Learn Mem 77:78-108.

Gandolfo F, Li C, Benda BJ, Schioppa CP, Bizzi E (2000) Cortical correlates of learning in monkeys adapting to a new dynamical environment. Proc Natl Acad Sci USA 97:2259-2263.

Greenough WT, Larson JR, Withers GS (1985) Effects of unilateral and bilateral training in a reaching task on dendritic branching of neurons in the rat motor-sensory forelimb cortex. Behav Neural Biol 44:301-314.

Hart M, Poremba A, Gabriel M (1997) The nomadic engram: overtraining eliminates the impairment of discriminative avoidance behavior produced by limbic thalamic lesions. Behav Brain Res 82:169-177.

Jacobs KM, Donoghue JP (1991) Reshaping the cortical motor map by unmasking latent intracortical connections. Science 251:944-947.

Jones TA, Chu CJ, Grande LA, Gregory AD (1999) Motor skills training enhances lesion-induced structural plasticity in the motor cortex of adult rats. J Neurosci 19:10153-10163.

Karni A, Meyer G, Rey-Hipolito C, Jezzard P, Adams MM, Turner R, Ungerleider LG (1998) The acquisition of skilled motor performance: fast and slow experience-driven changes in primary motor cortex. Proc Natl Acad Sci USA 95:861-868.

Kleim JA, Lussnig E, Schwarz ER, Comery TA, Greenough WT (1996) Synaptogenesis and Fos expression in the motor cortex of the adult rat after motor skill learning. J Neurosci 16:4529-4535.

Kleim JA, Vij K, Ballard DH, Greenough WT (1997a) Learning-dependent synaptic modifications in the cerebellar cortex of the adult rat persist for at least four weeks. J Neurosci 17:717-721.

Kleim JA, Swain RA, Czerlanis CM, Kelly JL, Pipitone MA, Greenough WT (1997b) Learning-dependent dendritic hypertrophy of cerebellar stellate cells: plasticity of local circuit neurons. Neurobiol Learn Mem 67:29-33. 
Kleim JA, Barbay S, Nudo RJ (1998a) Functional reorganization of the rat motor cortex following motor skill learning. J Neurophysiol 80:3321-3325

Kleim JA, Swain RA, Armstrong KA, Napper RM, Jones TA, Greenough WT (1998b) Selective synaptic plasticity within the cerebellar cortex following complex motor skill learning. Neurobiol Learn Mem 69:274-289.

Kleim JA, Barbay S, Cooper NR, Hogg TM, Reidel CN, Remple MS, Nudo RJ (2002a) Motor learning-dependent synaptogenesis is localized to functionally reorganized motor cortex. Neurobiol Learn Mem 77:63-77.

Kleim JA, Cooper NR, VandenBerg PM (2002b) Exercise induces angiogenesis but does not alter movement representations within rat motor cortex. Brain Res 934:1-6.

Laubach M, Wessberg J, Nicolelis MA (2000) Cortical ensemble activity increasingly predicts behaviour outcomes during learning of a motor task. Nature 405:567-571.

Niemann J, Winker T, Gerling J, Landwehrmeyer B, Jung R (1991) Changes of slow cortical negative DC-potentials during the acquisition of a complex finger motor task. Exp Brain Res 85:417-422.

Nudo RJ, Jenkins WM, Merzenich MM (1990) Repetitive microstimulation alters the cortical representation of movements in adult rats. Somatosens Mot Res 7:463-483.

Nudo RJ, Wise BM, SiFuentes F, Milliken GW (1996a) Neural substrates for the effects of rehabilitative training on motor recovery after ischemic infarct. Science 272:1791-1794.

Nudo RJ, Milliken GW, Jenkins WM, Merzenich MM (1996b) Usedependent alterations of movement representations in primary motor cortex of adult squirrel monkeys. J Neurosci 16:785-807.

Pearce AJ, Thickbroom GW, Byrnes ML, Mastaglia FL (2000) Functional reorganisation of the corticomotor projection to the hand in skilled racquet players. Exp Brain Res 130:238-243.

Plautz EJ, Milliken GW, Nudo RJ (2000) Effects of repetitive motor training on movement representations in adult squirrel monkeys: role of use versus learning. Neurobiol Learn Mem 74:27-55.
Porter R, Lemon R (1995) Corticospinal function and voluntary movement. Oxford: Clarendon.

Remple MS, Bruneau RM, VandenBerg PM, Goertzen C, Kleim JA (2001) Sensitivity of cortical movement representations to motor experience: evidence that skill learning but not strength training induces cortical reorganization. Behav Brain Res 123:133-141.

Rioult-Pedotti MS, Friedman D, Hess G, Donoghue JP (1998) Strengthening of horizontal cortical connections following skill learning. Nat Neurosci 1:230-234.

Rose SP, Stewart MG (1999) Cellular correlates of stages of memory formation in the chick following passive avoidance training. Behav Brain Res 98:237-243

Sanes JN, Donoghue JP (2000) Plasticity and primary motor cortex. Annu Rev Neurosci 23:393-415.

Sirevaag AM, Black JE, Greenough WT (1991) Astrocyte hypertrophy in the dentate gyrus of young male rats reflects variation of individual stress rather than group environmental complexity manipulations. Exp Neurol 111:74-79.

Sterio DC (1984) The unbiased estimation of number and sizes of arbitrary particles using the disector. J Microsc 134:127-136.

Turner AM, Greenough WT (1985) Differential rearing effects on rat visual cortex synapses. I. Synaptic and neuronal density and synapses per neuron. Brain Res 329:195-203.

Ungerleider LG, Doyon J, Karni A (2002) Imaging brain plasticity during motor skill learning. Neurobiol Learn Mem 78:553-564.

VandenBerg P, Kleim J (2001) The ontogeny of post-ischemic diaschisis. Soc Neurosci Abstr 28:728.

Whishaw IQ, Pellis SM (1990) The structure of skilled forelimb reaching in the rat: a proximally driven movement with a single distal rotatory component. Behav Brain Res 41:49-59.

Withers GS, Greenough WT (1989) Reach training selectively alters dendritic branching in subpopulations of layer II-III pyramids in rat motorsomatosensory forelimb cortex. Neuropsychologia 27:61-69. 